\title{
Laboratory studies on influence of transverse cracking on chloride-induced corrosion rate in concrete
}

\author{
Yongsheng $\mathrm{Ji}^{* \mathrm{a}, \mathrm{b}}$, Yijie $\mathrm{Hu}^{\mathrm{b}}$, Linglei Zhang ${ }^{\mathrm{b}}$, Zhongzheng Bao ${ }^{\mathrm{b}}$ \\ a. State Key Laboratory for Geomechanics and Deep Underground Engineering, China University of Mining and \\ Technology, Xuzhou 221116 China
}

b. Jiangsu Key Laboratory of Environmental Impact and Structural Safety in Engineering, China University of Mining and Technology, Xuzhou, Jiangsu, China, 221008

\begin{abstract}
To clarify the corrosion mechanism of steel induced by transverse crack, a study on the influence of crack widths and epoxy coating on corrosion of steel bars in cracked concrete is presented here. Microcell and macrocell corrosions of bars were investigated on single crack specimens with crack widths of $0.08,0.26,0.38$ and $0.94 \mathrm{~mm}$. The entire study was carried out in an artificially created chloride ion-induced corrosion environment. The results show that the steel in cracks was activated once the transverse crack occurred on concrete element, and the macrocell corrosion must co-exist with microcell corrosion of reinforcements in test specimens with transverse crack. The macrocell current of steel elements were separated from the crack width, and the wider the transverse crack is, the higher corroded area and the greater microcell current of the rebar is. Oxygen and water go into concrete through crack instead of through concrete cover. The epoxy coating cannot prevent the occurrence and propagation of crack, so it was not effective to prevent corrosion of steel bars in cracked concrete.
\end{abstract}

Key words: Concrete; Transverse Crack; Rebar; Corrosion rate; Macrocell; Microcell

\section{Introduction}

Presence of damage and cracks in concrete structures is a major concern for the owners and operators of the concrete infrastructures[1-2]. Once a crack is formed, it provides an easy access for ingress of water, chloride ions and oxygen to the steel surface, resulting in accelerating corrosion of steel reinforcement[3-6]. The service life of concrete infrastructure is drastically affected by presence of cracks. Therefore, to accurately predict the service life of the structures the influence of cracks should be accounted for in service life prediction models.

Cracks in concrete regarding steel corrosion may include longitudinal cracks (cracks parallel to rebar)and transverse cracks (cracks perpendicular to rebar). Longitudinal cracks are usually generated as a result of rust expansion induced by corrosion[7-9]. On the other hand, transverse cracks are usually caused by loading, which may produce localized corrosion at the tip of the intersecting crack.

A debate among the researchers on relationships between transverse crack width and corrosion rate has been continuing since long ago [10-14]. Several researchers [10-12] suggested that transverse cracks allow aggressive species to penetrate faster into the reinforced concrete thereby accelerating corrosion of the steel and reducing the service life of structures. However, others [13-14] supported that, even though transverse cracks accelerate the initiation of corrosion and induce localized damage to the reinforcing steel, there are little correlations between crack width and corrosion rates. It is expected that with any size of cracks, the corrosion rate of steel bars in concrete will depend much more on the surrounding concrete (i.e., concrete resistance, oxygen permeability, and chloride ion content) rather than crack widths. Based on these studies, several design codes [15-17]limit transverse crack widths to avoid the attack of chloride salt to the reinforcement. However, European design code[18] suggested that limiting transverse crack widths is no means to control the rate of rebar corrosion.

"Contact person for the paper: Tel: 86-137-7598-6533, 1-519-888-4567 x38718; E-mail: jiyongsheng@cumt.edu.cn 
The significant characteristic of localized corrosion is that the macrocell corrosion must co-exist with microcell corrosion of reinforcements in concrete [19]. The corrosion of rebar at transverse crack is a typical local corrosion for reinforced concrete structure [20-21]. The first viewpoint mentioned above comes from the research results that there are little relationships between transverse crack width and macrocell current. Not only the microcell corrosion of active rebar itself at crack zone was not considered, but also the hypothesis is lack of experimental verification that oxygen and water for cathode reaction of macrocell corrosion go into concrete through concrete cover instead of through crack. However, the reason for the above second viewpoints is that some researchers equate the corrosion mechanism of steel in cracked concrete to that of steel exposed to atmosphere, ignoring macrocell corrosion between active steel at transverse crack and passive steel in sound concrete.

Against the above background, this study was conducted to evaluate the relative contributions of the macro and micro cell components to the total corrosion of steel which was induced by chloride in a reinforced concrete member with bending crack. Microcell and macrocell corrosions of bars were investigated on single crack specimens with crack widths of $0.08,0.26,0.38$ and $0.94 \mathrm{~mm}$. and a study on the influence of epoxy coating on corrosion of steel bars in cracked concrete is presented here to determine the supply path of oxygen and water for macrocell corrosion.

\section{Theoretical}

\subsection{Corrosion mechanism of steel induced by transverse crack}

Once the transverse crack appears on concrete element due to the existence of load, the brittle concrete cover is not able to prevent the vertical extension of crack. As a result, the crack will extend to the steel surface rapidly. External corrosive media, such as chloride salt, can reach the steel surface regardless of the dimension of crack, which causes the steel corrosion due to its conversion from being passive to being active. The existence of crack has more significant influence on steel corrosion in concrete than crack width when the structure life time is taken into consideration.

The corrosion of rebar at transverse crack is a typical local corrosion for reinforced concrete structure (Fig.1). There is the electrochemical potential difference between active area (passivity broken) at crack as an macroanode and passive area (intact passivity) in sound concrete as a macrocathode, which is the driving force for the macrocell corrosion. The macrocell corrosion current between the active and passive steel surfaces further expedite the corrosion process on the surface of the active steel. On this corroded surface at crack there are incalculable dense and tiny corrosion pits. A galvanic corrosion coupling comes into being between the steel in each corrosion pit and weeny area arounding the pit, the sizes of these galvanic corrosion cells are very small, so that the morphology of pitting will be less evident. Therefore, on a macroscale, the corrosion on the external surface of the reinforced steel is general. The countless dense and tiny galvanic corrosion macrocells can be viewed as microcell corrosion.

The most simple and most probable reactions that could occur are:

Anodic reaction at transverse crack:

$$
2 \mathrm{Fe} \rightarrow 2 \mathrm{Fe}^{2+}+4 \mathrm{e}
$$

Cathodic reaction in both transverse crack for microcell and sound concrete for macrocell:

$$
4 \mathrm{e}+\mathrm{O}_{2}+2 \mathrm{H}_{2} \mathrm{O} \rightarrow 4 \mathrm{OH}^{-}
$$

Both macrocell and microcell corrosion mechanisms could play significant roles, and the total corrosion could be underestimated if each of two is overlooked. 


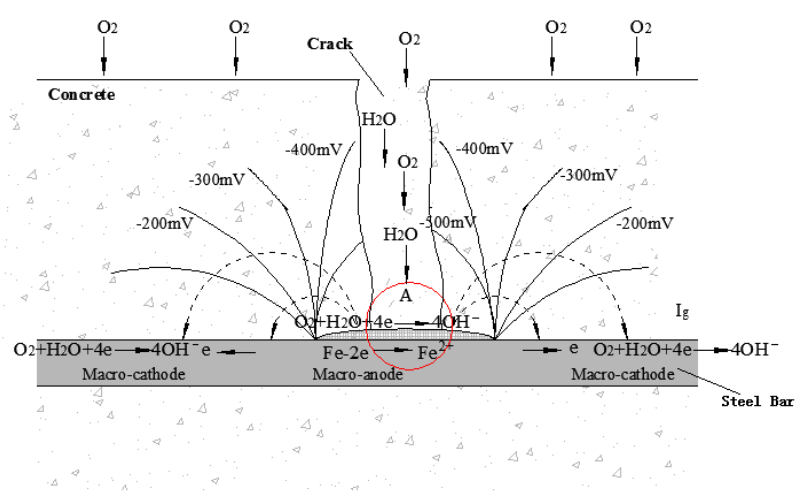

(a) Corrosion of steel bar at flexural crack

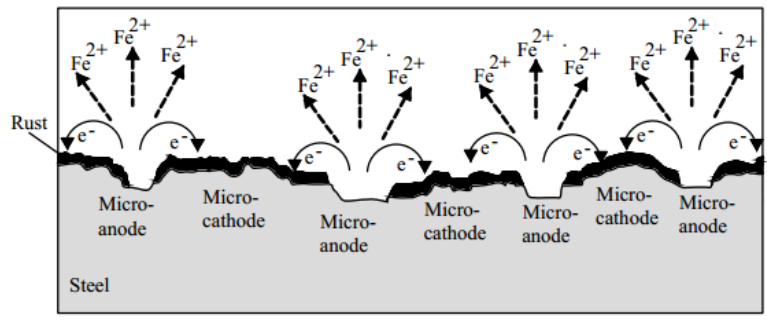

(b) Amplified area A

Fig.1. Schematic illustration of microcell and macrocell corrosion of galvanized steel at crack

Macrocell corrosion current is determined by the corrosion potential difference between the activated zone and surrounding passive zone on steel bar, and it is irrelevant to the crack width. The increase of crack width does not only enlarge the area of active zone on steel bar, but also introduces oxygen and water into crack directly through its opening to atmosphere environment. Consequently, microcell current is increased significantly and rapidly for steel bar in crack, and the microcell corrosion current is much greater than that of macrocell.

\subsection{The electrochemistry of corrosion of steel bar in cracked concrete}

The corrosion current and the corrosion potential of steel immersed in any given electrolyte can be theoretically determined by Evans diagrams, i.e., the graphic representation of anodic and cathodic polarization curves, based on electrochemical principles [22]. These diagrams are used in this work to illustrate and to discuss the mechanisms of a macrocell formation resulting from transverse crack of concrete structures and their effects on the rate of corrosion of reinforcements. A simple two-electrode macrocell corrosion system consists of one passive steel (electrode 1) and one active steel (electrode 2) as illustrated in Fig. 2. Curve $\mathrm{C}_{1}, \mathrm{C}_{2}$ in diagram are the cathodic polarization curves of active and passive reinforcing steel, and Curve $\mathrm{A}_{1}, \mathrm{~A}_{2}$ are the anodic polarization curves of active and passive reinforcing steel. When these two electrodes are insulated from each other, the corrosion current of the passive steel (electrode 1) is $I_{\text {corr }}$ and the corrosion current of the active steel (electrode 2) is $I_{\text {corr2 }}$, thus the total corrosion current is the sum of them:

$$
I_{\text {total }}=I_{\text {corr } 1}+I_{\text {corr } 2}
$$

However, these two electrodes are actually in electrical contact in concrete, the potentials of the two steels will shift to a common potential and reach a new equilibrium, assuming the resistance of the electrolyte is negligible. The active steel, which has a more negative potential $\left(E_{\text {corr2 }}\right)$, will be anodically polarized to a more positive potential $E_{\text {corr }}$, while the passive steel, having a more positive potential $\left(E_{\text {corrl }}\right)$, will be cathodically polarized to a more negative potential $E_{\text {corr, }}$ as shown in Fig. 2. Accordingly, the anodic dissolution current in the active steel is increased from $I_{\text {corr } 2}$ (the corrosion current before coupling) to $I_{\mathrm{a} 2}$ ' and the cathodic current decreased from $I_{\text {corr } 2}$ to $I_{\mathrm{c} 2}$ '. In the passive steel however, the anodic current is reduced from $I_{\text {corr } 1}$ to $I_{\mathrm{a} 1}$ ' and the cathodic current increased from $I_{\mathrm{corr} 1}$ to $I_{\mathrm{c} 1}$ '. At the new equilibrium, the whole electrode system will have the following relation: 


$$
I_{\mathrm{cl}}{ }^{\prime}+I_{\mathrm{c} 2}{ }^{\prime}=I_{\mathrm{a} 1}{ }^{\prime}+I_{\mathrm{a} 2}{ }^{\prime}
$$

Besides the microcell corrosion, in which electrons are transferred from the anodic to cathodic sites in each of the electrodes, some electrons are also transferred from one electrode (the active steel) to the other (the passive steel), resulting in a galvanic current (macrocell current) $I_{\mathrm{g}}$ :

$$
I_{\mathrm{g}}=I_{\mathrm{c} 1}{ }^{\prime}-I_{\mathrm{a} 1}{ }^{\prime}=I_{\mathrm{a} 2}{ }^{\prime}-I_{\mathrm{c} 2}{ }^{\prime}
$$

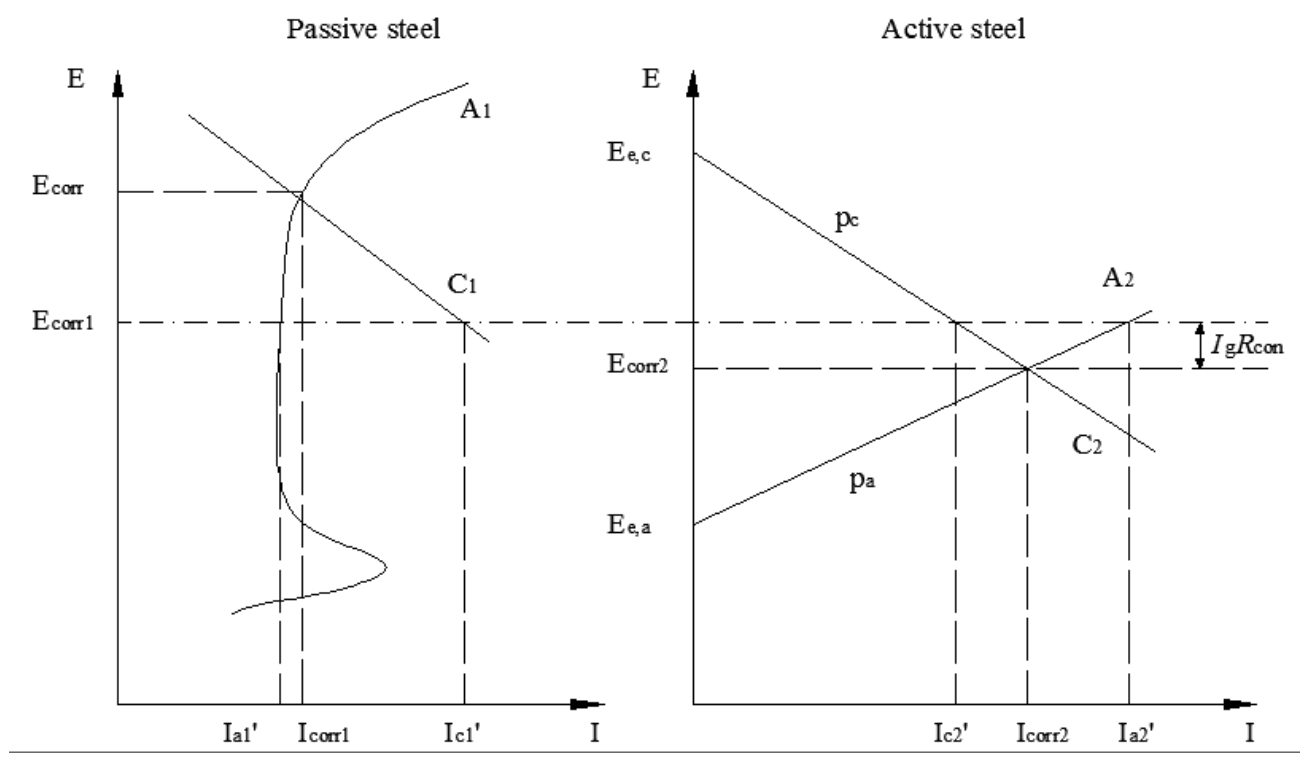

Fig.2. Macrocell current formed between passive steel and active steel

\section{Experimental}

\subsection{Experimental Program}

\subsubsection{Preparation of specimens}

Four concrete specimens were cast to study the response of steel embedded in cracked concrete. The specimen geometry and dimensions are shown in Fig.3. The rebars in the specimens are HPB235 rebars with diameter of 12 $\mathrm{mm}$. Each specimen was made with a steel bar that was composed of seven steel elements for the purpose of measuring macrocell and microcell corrosion currents. One 20-mm long bars and six 75-mm long bars were used for each specimen. Lead wires were soldered at both ends of the segments before these segments were joined with epoxy resin of high insulating capacity to form a 690 -mm long reinforcement. The central segment, labeled "A", was positioned such that it was centered on the crack. The other segments, labeled “ $\mathrm{C} 1$ ” 、 “C2" 、 "C3" and

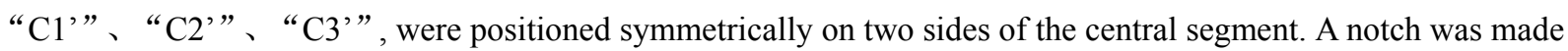
( $0.2 \mathrm{~mm}$ width*5 $\mathrm{mm}$ depth) at the center across the specimen in order to fix the location of the crack at the center of the specimen. Two counter steel bars with 700-mm long were set at the tensile side to carry the bending load and produce the bending cracks without destroying the special steel elements.

\subsubsection{Concrete materials}

All beams were cast using concrete with the same mix proportions with 28 days target strength of $35 \mathrm{MPa}$. P.O32.5 ordinary Portland cement (according to the China Standard GB175-1999) was used for all specimens. Coarse aggregate of crushed limestone with a maximum particle size of $15 \mathrm{~mm}$ was used. Fine aggregate was river sand with fineness modulus of 2.65. Both aggregates complied with the requirement of ASTM stands for American Society for Testing of Materials. The mix proportions of concrete used for casting are as follows: cement: water: sand: gravel $=1: 0.55: 2.3: 4.5$. The concrete cover depth is $15 \mathrm{~mm}$. 


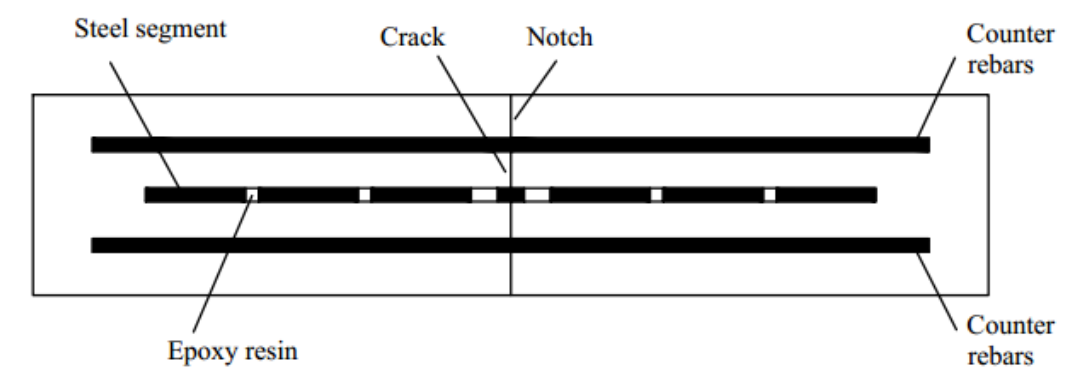

Fig.3 Schematic of specimens
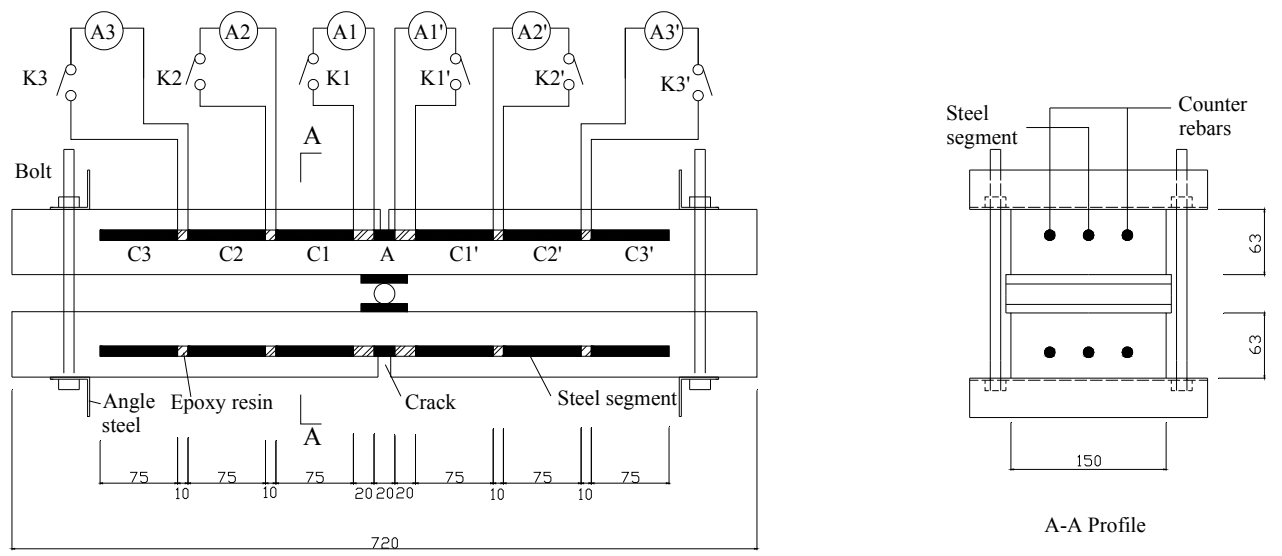

Fig.4 Design of test specimens

Note: "A" stands for the central segment; "C1", "C2", "C3" and "C1' ", "C2' ", "C3' " stand for the other segments; "A1", "A2", "A3" and "A1' ", "A2' ", "A3' " stand for amperemeters; "K1", "K2", "K3" and "K1' ", "K2' ", "K3' " stand for Switches.

\subsubsection{Formation of cracks and control of crack width}

The specimens were cured in a high-humidity environment with $95 \%$ relative humidity (RH) and $25{ }^{\circ} \mathrm{C}$ until the age of 28 days. The specimens were cracked with specified crack widths by bending (Fig.4). The specimen was subjected to flexural loading by the turning the nuts to initiate a crack along the plastic insert. The surface crack widths were checked with an optical microscope which provides $60 \mathrm{X}$ magnification. The crack widths were controlled by adjusting flexural loading. The surface crack widths in the beams are shown in Tabel 1.

Tab.1 Summary of the experimental specimens

\begin{tabular}{l|c|c|c|c}
\hline Beam & AK1 & AK2 & AK2 & AK2 \\
\hline Crack width/mm & 0.08 & 0.26 & 0.38 & 0.94 \\
\hline
\end{tabular}

\subsubsection{Exposure conditions}

The specimens were subsequently subjected to periodic wetting and drying cycles to accelerate the corrosion process. Each wetting-drying cycle involved $0.2 \mathrm{~h}$ spraying with a $5 \% \mathrm{NaCl}$ solution (by weight) followed by a $11.8 \mathrm{~h}$ drying period - laboratory atmosphere with about $75 \%$ R.H. and $30^{\circ} \mathrm{C}$. In order to evaluate the corrosion behaviour of reinforcing steels in the cracked concrete beams, the electrochemical investigations were conducted on the specimens in a month.

Then an epoxy resin coating was applied to all surfaces of AK2 specimen except for the crack. After 24 hour, the microcell current of all steel elements and the macrocell current between active steel at transverse crack and 
passive steel in sound concrete were measured to determine the supply path of oxygen for macrocell corrosion.

\subsection{Measurements}

\subsubsection{Measurements of corrosion potential}

The corrosion potential of the reinforcing steel was measured by the half-cell potential. The method is used to locate points where corrosion must be under development but without apparent manifestation. The classification criteria adopted are in accordance to ASTM C876[21] and are reproduced in Table 2. The reference electrode of the values shown in Table 1is related to copper/copper sulphate (CSE).

Table 2 Ranges of half-cell corrosion potential related to the corrosion probability[21].

\begin{tabular}{c|c}
\hline Corrosion potential (Ecorr) (mV vs. CSE) & Corrosion probability \\
\hline$<-350 \mathrm{mV}$ & $90 \%$ \\
\hline$(-350 \mathrm{mV})-(-200 \mathrm{mV})$ & Uncertain \\
\hline$>-200 \mathrm{mV}$ & $10 \%$ \\
\hline
\end{tabular}

\subsubsection{Measurement of macrocell current}

Zero resistance ammeters were used to measure the inflow and outflow of currents of an element of single crack specimens. In this case, all steel bars were electrically connected with each other. Fig. 5 shows the details of the measurement. The following equation was used to calculate the macrocell current of a steel element [23]:

$$
I_{\text {gi }}=I_{\text {out }}-I_{\text {in }}
$$

Where $I_{\mathrm{gi}}$ is macrocell current in $\mathrm{mA}$ of an element; $\mathrm{I}_{\text {out }}$ is outflow current in $\mathrm{mA}$ from the steel element; $\mathrm{I}_{\mathrm{in}}$ is inflow current in $\mathrm{mA}$ to the steel element; If the value of $I_{\mathrm{gi}}$ is positive, the macrocell current is anodic and if negative, the macrocell current is cathodic.

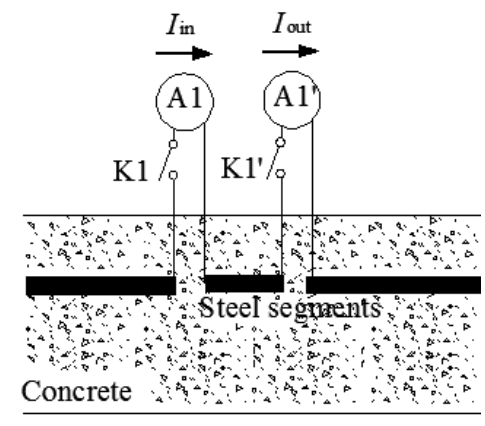

Fig. 5 Measurement of macrocell current

The steel segments were connected into the system in sequence $\mathrm{n}$ order to compare the influence of cathode area on macrocell current. Switch K1 and K1' were first closed. 5 minutes later, readings from the zero resistance ammeters were recorded. Then K2 and K2' were also connected into the system. Finally all Switchs were connected for 5 minutes and the corresponding readings were recorded each time. The macrocell current between the steel elements may be calculated by the equation (6).

\subsubsection{Measurement of microcell current}

The corrosion rate was determined using the equipment called CORTEST applying the linear polarization resistance technique to estimate corrosion rate. The linear polarization technique is a non-destructive method for assessing the instantaneous corrosion current. It has been widely used in monitoring corrosion of laboratory specimens, as well as field structures [24,25]. The experimental setup of the measurement of the corrosion current is shown in Fig. 6. A three electrodes device was used. The rebar segments were employed as a working electrode. A saturated copper/copper sulfate electrode was used as reference electrode. All potentials are referred to the saturated copper/copper sulfate electrode. The stainless rebar was used as counter electrode. Fig. 3 shows the details of the measurement. In this case, the investigated steel bars were isolated from others just before the measurements by removing the outside connections. From this arrangement, the microcell corrosion of each steel 
element was evaluated.

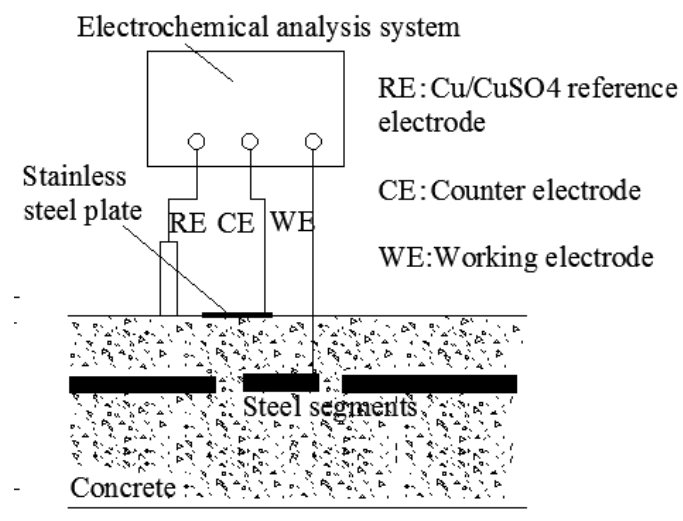

Fig.6 Measurement of microcell current

\subsubsection{Observation of steel bars}

After the test period, all specimens were broken for visual observation of the location of corrosion of the steel bars.

\section{Results and discussion}

\subsection{Distribution of corrosion potentials}

Half-cell potential measurements were performed on individual segments in the open and closed modes configuration, respectively. The distribution of potentials in the specimens obtained using an SCE placed on the concrete surface were shown in Fig.7. It showed that with all switches open, the differences in the steady half-cell potentials of the segments $\mathrm{C} 1$ through $\mathrm{C} 3$ and $\mathrm{C} 1$ ' through $\mathrm{C} 3$ ' were not significant. There was however a large difference in the potentials of the segment located at the crack when compared with the potentials of the segments away from the crack. The potential difference between the segment at crack and segments away from crack was in the range $400 \sim 450 \mathrm{mV}$. The measured potentials from the open mode suggest that the steel segment at crack was undergoing active corrosion while the steel segments away from the crack are in a passive state.

Once the measured currents indicated a macrocell steady-state with all switches closed, the potentials of the segments were measured and the values of potentials were shown in Fig.7. It could be seen that the shift away from the potential in open configuration was apparent from the graph. At macrocell steady state, the potential difference between segment $\mathrm{A}$ and segments $\mathrm{C} 1$ through $\mathrm{C} 3$ and $\mathrm{C} 1$ ' through $\mathrm{C} 3$ ' decreased when compared to the open mode. The potential difference between the different segments of the cathode did not appear to be significant. The potential of the steel segment A was elevated above the potential associated with active microcell corrosion (obtained previously in the open state). The potential of the segments $\mathrm{C} 1$ through $\mathrm{C} 3$ and $\mathrm{C} 1$ ' through $\mathrm{C} 3$ ' ere depressed below the potential for passive steel in concrete (obtained previously in the open mode). Under the same climate environment conditions, the width of transverse crack in concrete did not have influence on the magnitude and distribution of corrosion potentials in the open and closed modes configuration. 


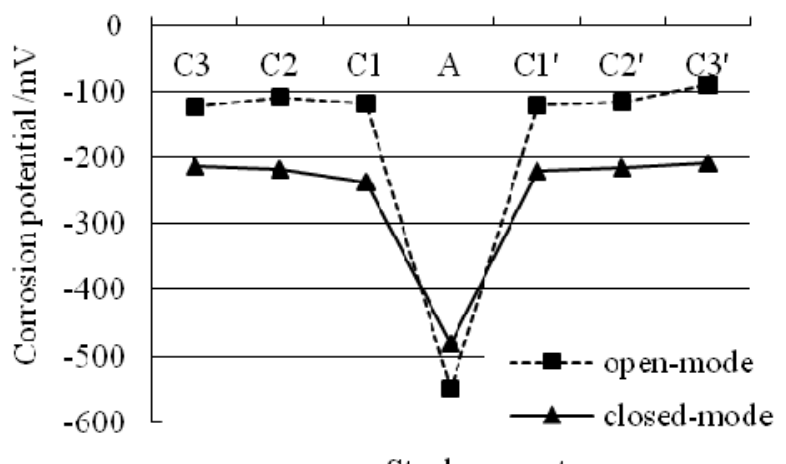

Steel segments

(a) $\mathrm{AK} 1$

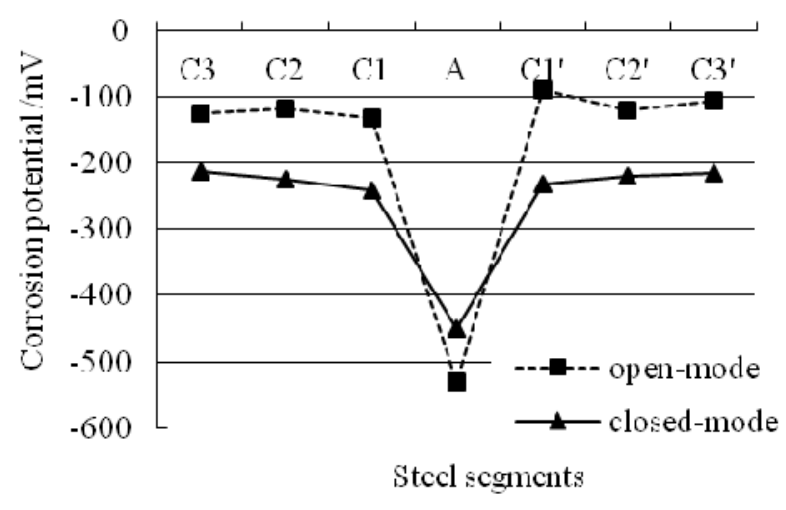

(b) $\mathrm{AK} 2$

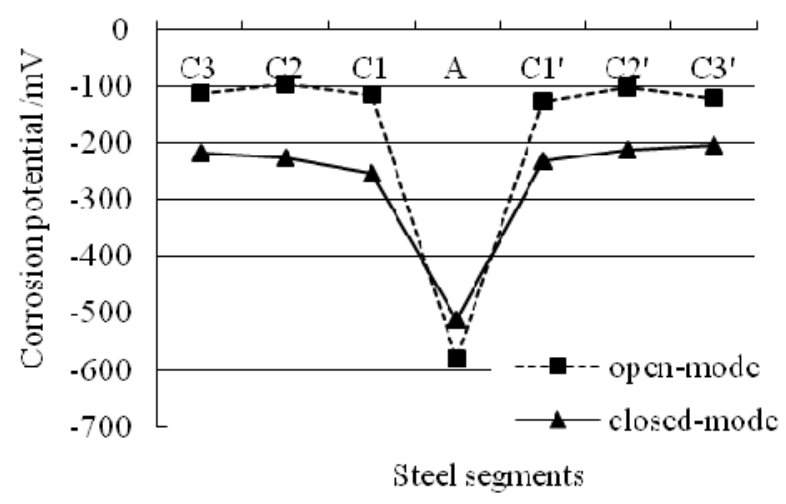

(c) $\mathrm{AK} 3$ 


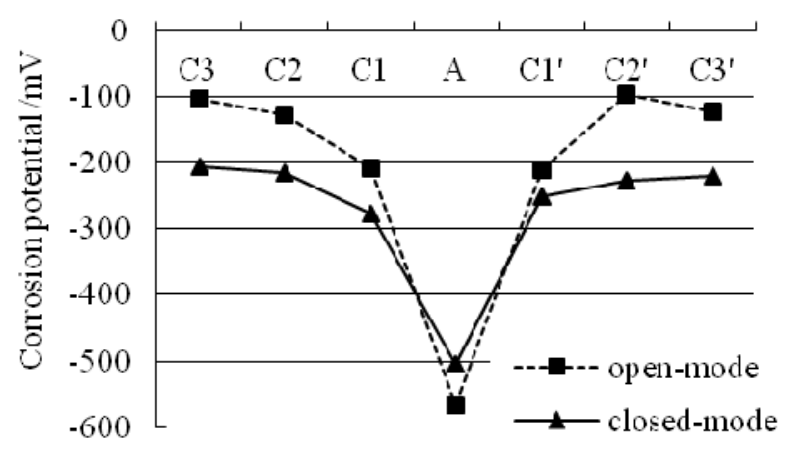

Steel segments

(d) $\mathrm{AK} 3$

Fig.7 Distribution of corrosion potentials in the specimens

\subsection{Distribution of ammeter readings}

With all switches close, the direction and distribution of macrocell corrosion current in the specimens were shown in Fig.8. It was found that the direction of current was from the steel segments located in cracks to the segments located towards its both ends. The greatest reading was given by the ammeter most close to the crack, and the current readings decreased gradually towards two ends along with the distance away from the crack. When the switches were closed one by one in order, readings from zero resistance ammeters are demonstrated in Fig.9. Under the same climate environment conditions, the width of transverse crack in concrete did not have influence on the magnitude and distribution of the current readings. It can be concluded that external corrosion media, such as chloride salt, was able to reach the surface of steel bar along the crack regardless of crack dimension. The rebar lose their initial passive state and became active, initiating corrosion. It means that the existence of crack has dominating influence on steel corrosion in concrete element regarding the service life of reinforced concrete structure.
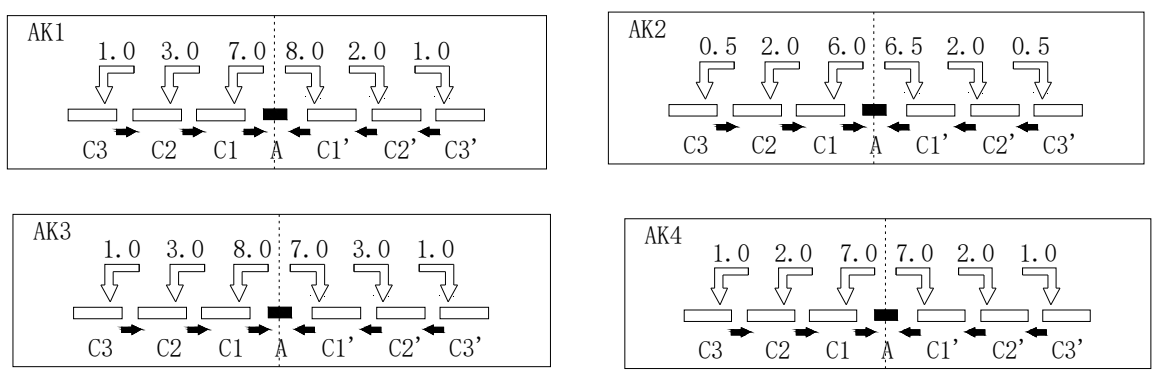

Fig.8 Direction and distribution of macrocell current in the specimens

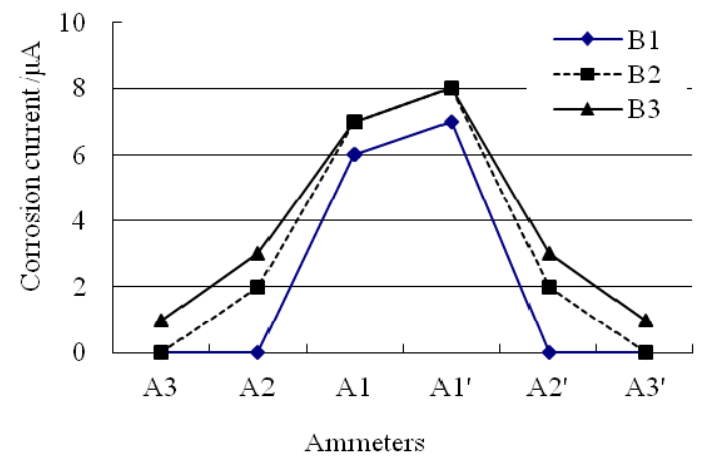

(a) $\mathrm{AK} 1$ 


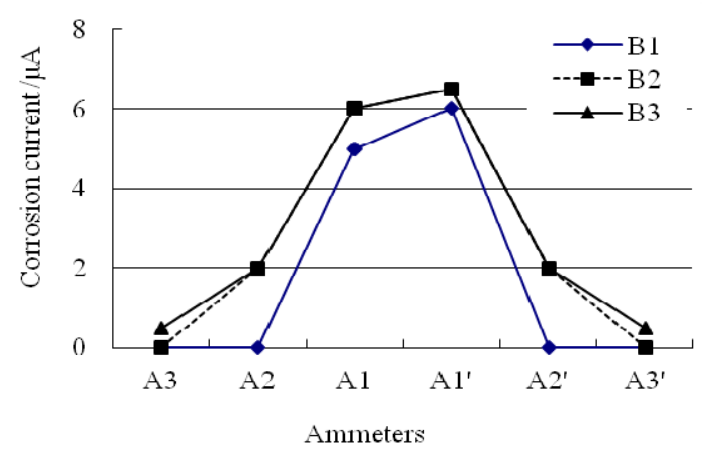

(a) $\mathrm{AK} 2$

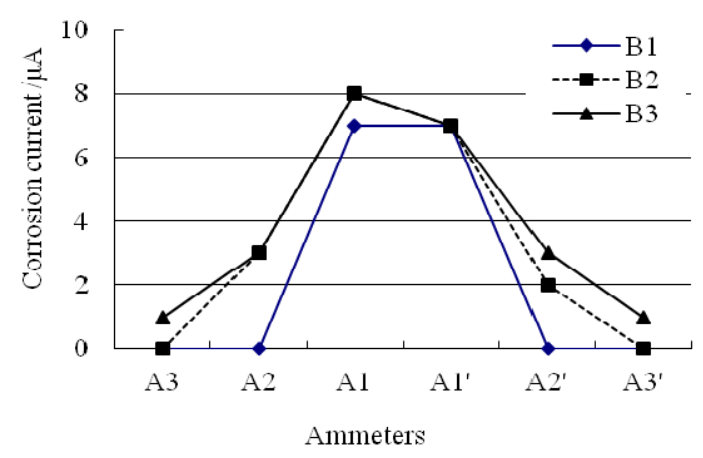

(a) $\mathrm{AK} 3$

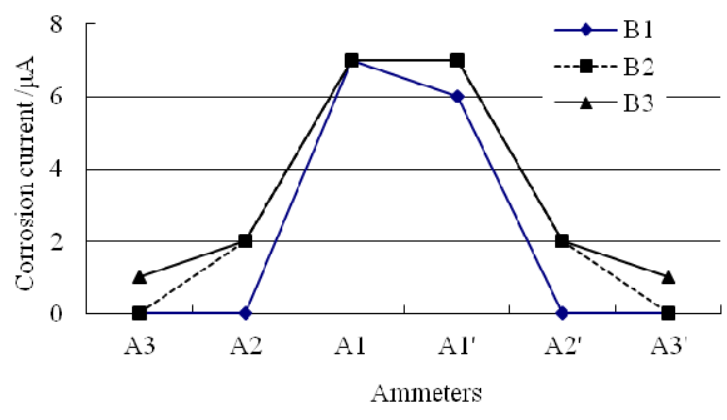

(a) $\mathrm{AK} 4$

Fig.9 Readings of Zero Resistance Ammeters Used to Measure the Inflow and Outflow of Currents Note: B1stands for $\mathrm{K} 1+\mathrm{K} 1{ }^{\prime}, \mathrm{B} 2$ stands for $\mathrm{K} 1+\mathrm{K} 2+\mathrm{K} 1{ }^{\prime}+\mathrm{K} 2{ }^{\prime}$, and $\mathrm{B} 3$ stands for $\mathrm{K} 1+\mathrm{K} 2+\mathrm{K} 3+\mathrm{K} 1{ }^{\prime}+\mathrm{K} 2{ }^{\prime}+\mathrm{K} 3{ }^{\prime}$.

\subsection{Distribution of steel macrocell corrosion current}

It is possible to determine for each region of the reinforcing steel whether more electrons have been received than sacrificed (macrocathode) or vice versa (macroanode) by measuring the macrocell corrosion current between the steel segments. The macrocell corrosion currents for different steel segments were calculated by substituting the readings from ammeters into equation (6) and its distribution is shown in Fig.10. It is apparent that the macrocell corrosion current for steel segments located in cracks gave the greatest positive reading, which means that steel segments located in cracks acted as the anode and segments located away from crack acted as the cathode in corrosion macrocell. The anodic current equals to the sum of all the cathodic currents from surrounding steel segments. When switch K2 and K2' were closed after switch K1 and K1', macro-cathode area increased and anodic macrocell current from steel segments located in cracks increased slightly. After switch K3 and K3' were closed afterwards, macro-cathode area had a further increase, but there was no significant change for anodic macrocell current. The cathodic macrocell current in segments 1 and 1' adjacent to crack decreased slightly. However, due to the cathode area increase, the distribution area of cathodic current increased, and the cathodic 
current kept constant, which equaled to anodic macrocell current in steel located in crack.

It was proved that only a portion of the passive region located adjacent to the active steel, rather than the entire passive region all act as anodic for corrosion macrocell (as shown in Fig.11). Additionally, although the crack widths were different in four specimens, the magnitude and distribution pattern of macrocell corrosion current did not show significant difference. It implied that the macrocell corrosion current was determined by the corrosion potential difference between active steel and passive steel regardless of the crack width.

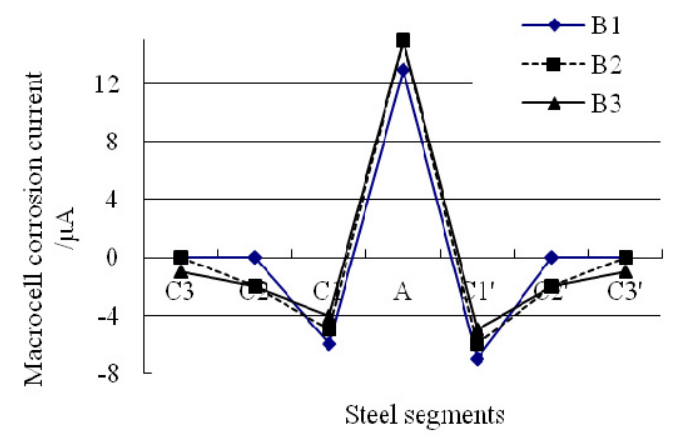

(a) AK1

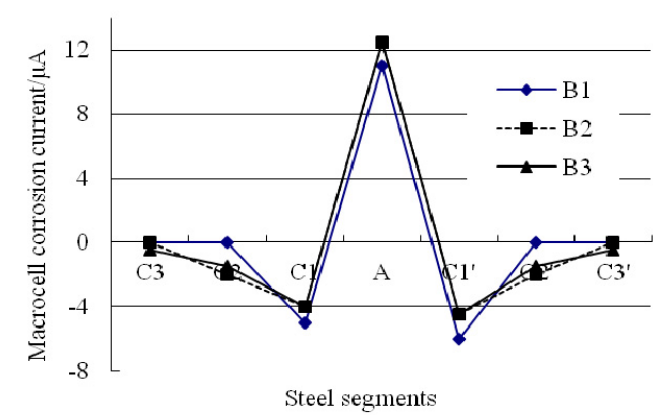

(b) AK2

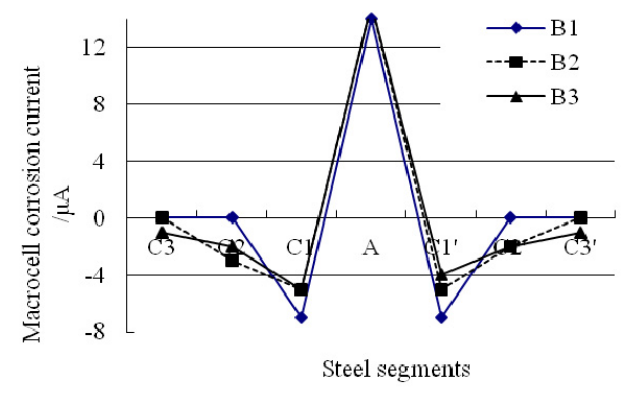

(c) AK3

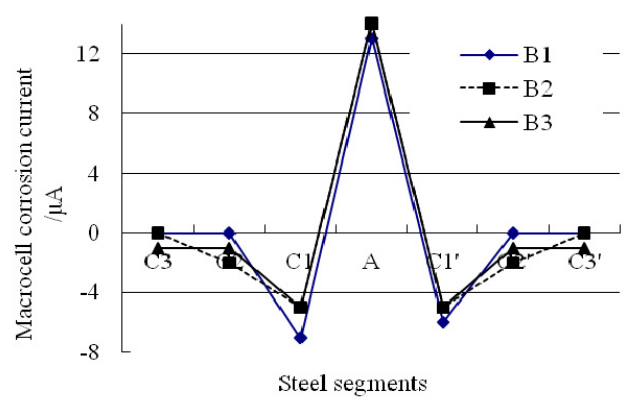

(d) $\mathrm{AK} 4$ 
Fig. 10 Distribution of macrocell current of steel elements (Different Crack widths)

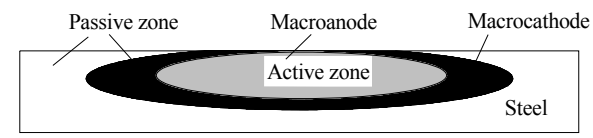

Fig.11 Distribution of macrocathode and macroanode of local corrosion cell

\subsection{Distribution of steel microcell corrosion current}

The distribution of microcell corrosion current in steel with different crack width is illustrated in Fig. 12. It shows that microcell corrosion current of the steel segment located at the crack was greatest, while it was very small in steel located in sound concrete. The reason is that the steel in cracks was activated due to the corrosion caused by direct exposure to chloride salts, while the steel located in sound concrete without crack was still passive. Compared with macrocell corrosion current, the microcell corrosion current for steel in crack is much greater. This is the evidence for the coexistence of corrosion macrocell and corrosion microcell in transverse crack area. Meanwhile, microcell corrosion rate was much greater than that of macrocell. From Fig.12, it can be summarised that along with the crack width increase, from $0.08 \mathrm{~mm}$ to $0.94 \mathrm{~mm}$, microcell corrosion current in cracks area increased significantly by 2.9 times. However, the crack width had negligible influence on microcell corrosion current of steel in the surrounding concrete area without crack. Based on our analysis, it can be concluded that along the increase of crack width, the active area of steel increased, the area of corrosion microcell increased correspondingly, which resulted in the increase of corrosion microcell current.

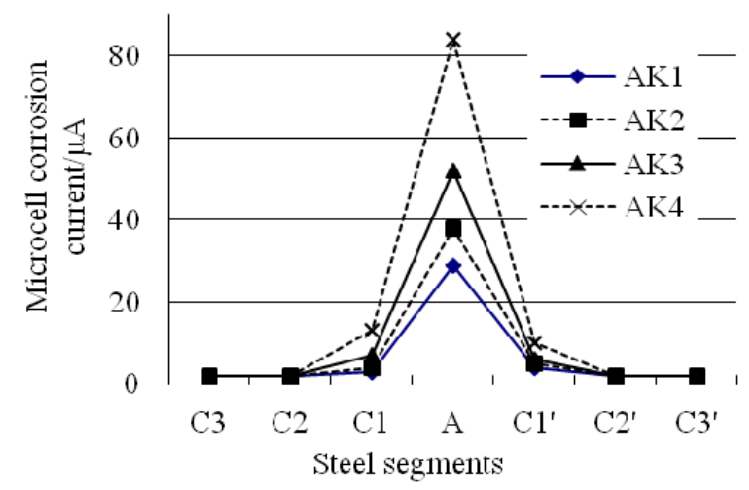

Fig.12 Distribution of Microcell current of Steel elements (Different Crack widths)

\subsection{Distribution of total corrosion current}

To distinguish between macrocell and microcell prominent corrosions, the maximum values of the measured macrocell and microcell corrosion electricity were compared. The total corrosion current can be obtained by adding the macrocell and microcell current of each steel segment in a specimen. The distribution of total corrosion current in steel segments located in cracks with different widths is shown in Fig.13. It shows that the total corrosion currents were greatest in steel segments located at cracks, while the total corrosion currents in steel segments in adjacent area were quite small. Especially for the steel segments, labeled " $\mathrm{C} 1$ " and " $\mathrm{C} 1$ " ”, which had directed contact to the active segment $\mathrm{A}$, the total corrosion currents were zero due to the cathodic protection from the active segment A. It proves that the cathodic protection effect on adjacent passive steel segments from the corrosion of activated steel segments was confined in limited area, which differed from the previous knowledge about the existence of small anode and great cathode in steel corrosion cell exposed to chloride-containing environment. 


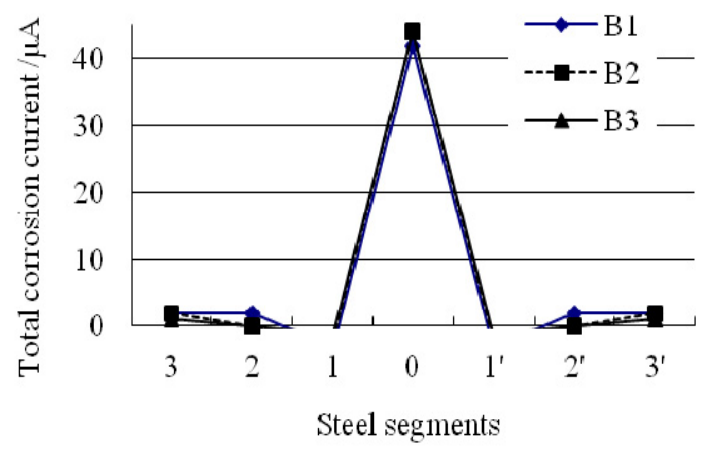

(a) $\mathrm{AK} 1$

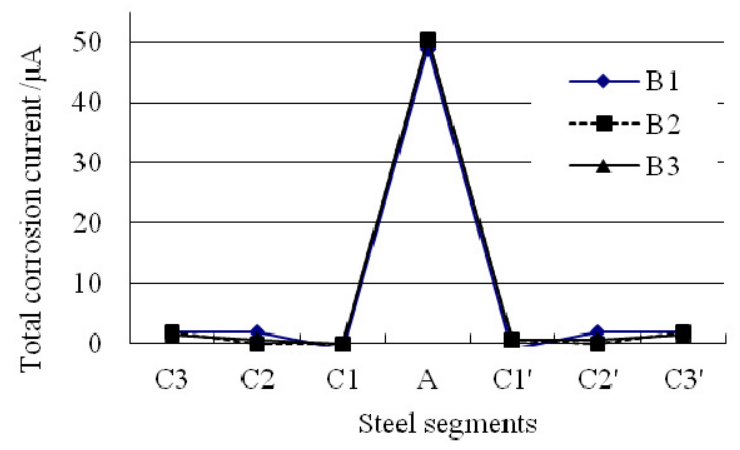

(b) $\mathrm{AK} 2$

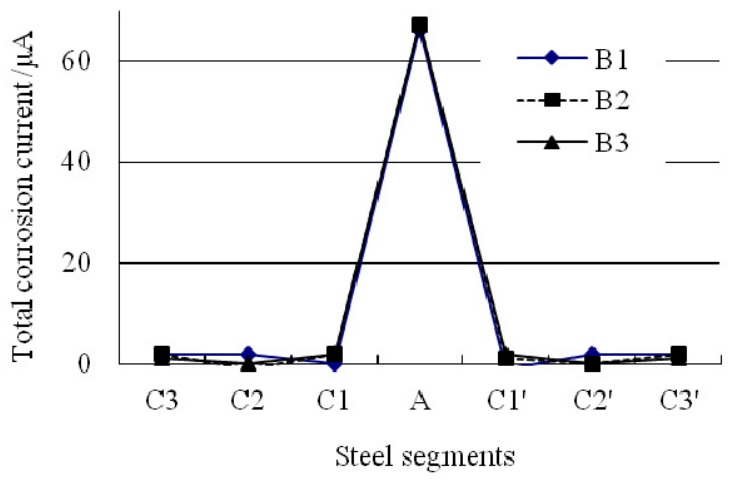

(c) $\mathrm{AK} 3$

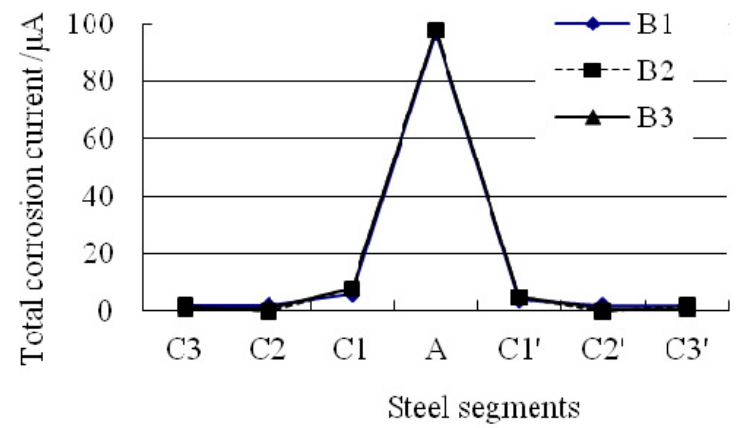

(d) $\mathrm{AK} 4$

Fig.13Distribution of Total Current of Steel Elements (Different Crack widths) 
After applying epoxy coating, the reading distribution of zero resistance ammeters, macrocell corrosion current, microcell current and total current distribution with keys closed in order is shown in Fig.14. A few conclusions were drawn from the comparison of Fig.14 with Fig.5 and Fig.7. The reading distribution of zero resistance ammeters and the macrocell corrosion currents in steel segments before and after applying epoxy coating did not change significantly. The microcell corrosion current only increased slightly for steel segments located at crack, while the microcell corrosion current in other steel segments remained almost the same as it was without epoxy coating. Although the steel segments in cracks were activated first, and became macroanode in corrosion macrocell with the adjacent area as macrocathode. However, the macrocathode of corrosion macrocell only included the limited area adjacent to cracks. Oxygen and water, which are required by macrocathodic reaction, mainly invaded in through cracks, instead of penetrating through the protection layer of sound concrete without cracks.

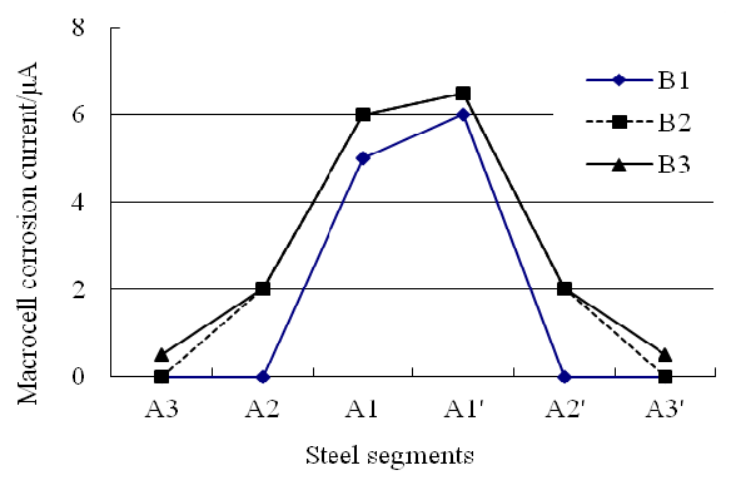

(a) Reading distribution of zero resistance ammeters

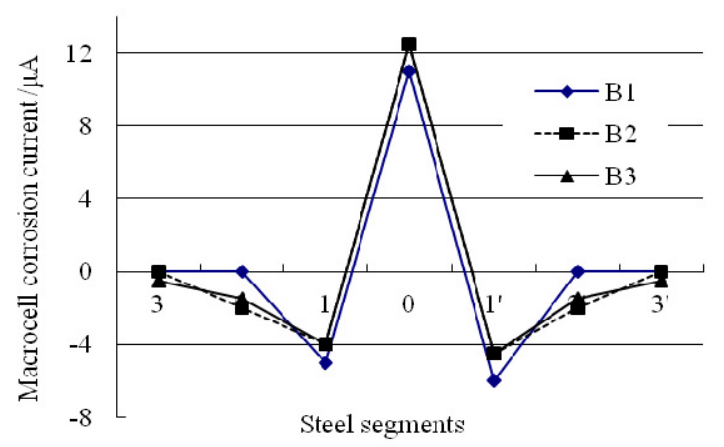

(b) Macrocell current distribution of steel corrosion

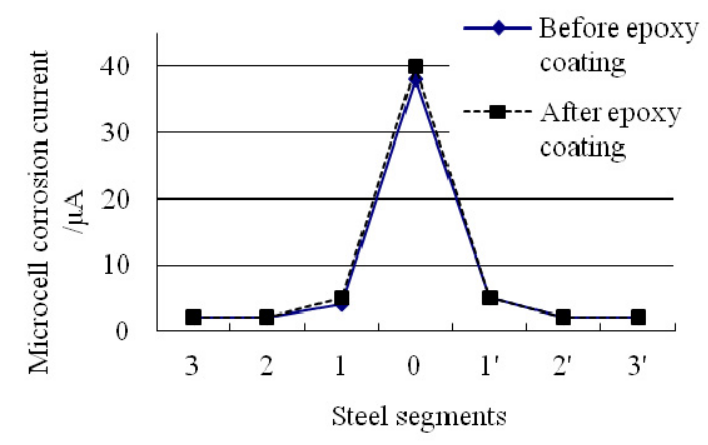

(c) Microcell current distribution of steel corrosion 


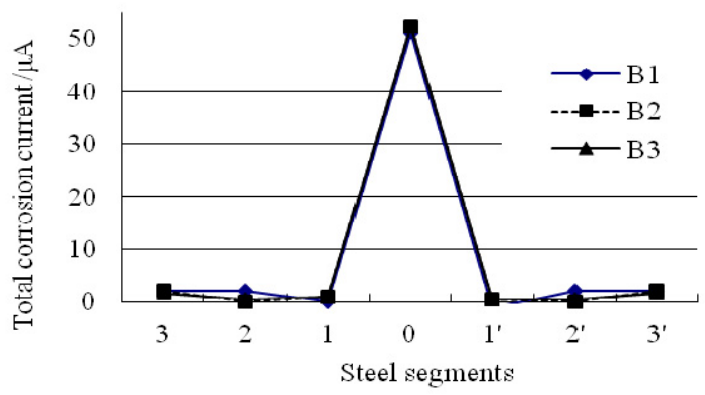

(d) Total current distribution of steel corrosion

Fig. 14. The Influence of epoxy coat on Distribution of Current of Steel Elements

After applying epoxy coating, the slight increase of microcell corrosion current in steel segment ' $\mathrm{A}$ ' was caused by experimental error, becasue the microcell corrosion current differed slightly for each measurement due to the dynamic process of steel corrosion in concrete. Oxygen and water required for corrosion reaction invaded in through crack directly, therefore applying epoxy coating on the surface of concrete cannot stop the occurrence and development of corrosion macrocell and microcell. Meanwhile, it is not effective to prevent the steel corrosion in cracks by increasing the thickness of concrete cover, increasing concrete quality and other similar methods.

\subsection{Visual examinations}

To verify the results of the current measurement the specimens were opened after 30 cycles and the positions of the cracks in the specimens as well as the corrosion degree were determined. The observation of corrosion surface on steel segments in cracks is shown in Fig.15. It is shown in this picture that the steel in cracks exhibit noticeable corrosion even with only the crack width of $0.08 \mathrm{~mm}$ (the minimum achievable width under this experiment condition) on specimen AK1. The reason is that once transverse crack occurs on concrete element, it will extend to the steel surface rapidly due to the load on concrete. Meanwhile, when the transverse crack occurred, the interface bond between the concrete and steel was destroyed. As a result, concrete and steel disconnected from each other due to the relative movement occurred on contacting surface of concrete and steel. Thereafter, oxygen and water easily entered the cracks and got contact with the surface of steel which is debonded with concrete in the previous process. The length of damaged area between steel bar and concrete can be clearly observed by injecting red ink into the crack of the specimen AK1(Fig.16). Therefore, the steel corrosion area was much larger than the crack width on the surface of concrete. Additional, from Fig.12, it was shown that the magnitude of steel corrosion area and its corrosion degree was determined by the concrete crack width. The wider the crack was, the severer the steel corrosion was in crack. The degree of corrosion was clearly related to the measured cumulative corrosion current, which is consistent with the above conclusion about the crack width influence on total corrosion current.

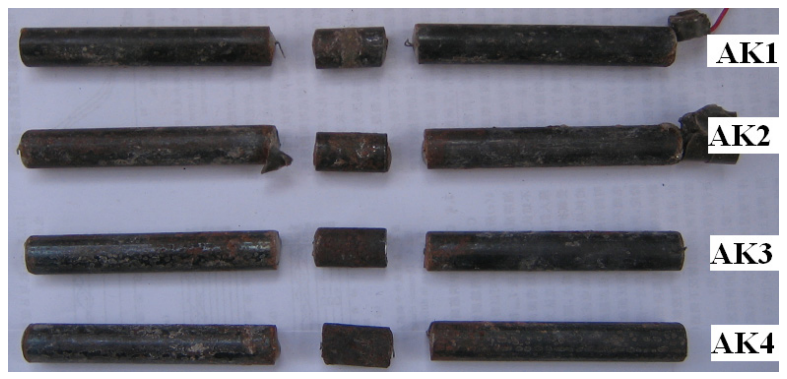

Fig.15 Corrosion shape of steel elements in cracked concrete 


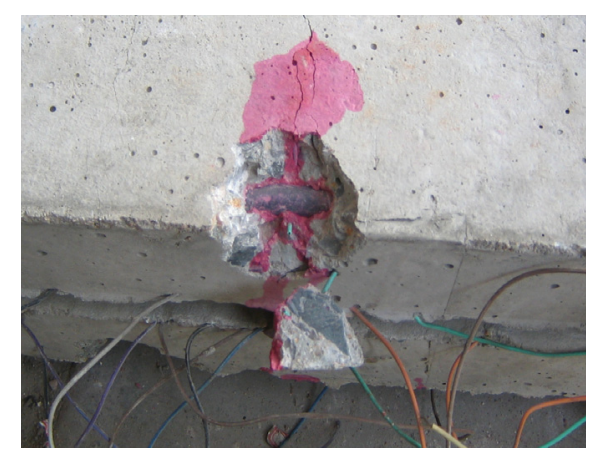

Fig.16 Picture of injecting red ink into crack of specimen AK1

\section{Conclusions}

In this study, the formation pattern of corrosion cell and the corrosion rate of rebars in concrete with transverse crack were investigated, tabulated and compared. The conclusions are as follows.

(1) The steel in cracks was activated once the transverse crack occurred on concrete element. The corrosion is characterized by the coexistence of microcell corrosion and macrocell corrosion. The microcell corrosion occurred in activated zone. Potential difference existed between the activated zone and the surrounding passive zone in steel, and macrocell corrosion took place with the activated zone as macroanode and the passive zone as macrocathode. The total corrosion current was the sum of macrocell corrosion current and microcell corrosion current.

(2) The width of transverse crack in concrete did not have influence on the magnitude and distribution of macrocell corrosion current, while it enlarged the area of activated zone on steel in cracks area. It results in the increase of microcell corrosion current. Therefore, it is necessary to control the width of transverse crack in concrete strictly to restrain the corrosion rate in cracks area.

(3) The steel in cracks contacted directly with atmosphere, oxygen and water required by the corrosion reaction invaded directly of into cracks instead of their penetration through the cover of sound concrete without cracks. Application of epoxy coating was unable to prevent the occurrence and propagation of macrocell and microcell corrosion to steel in crack. Additionally, it was not effective to prevent the steel corrosion in cracks by increasing concrete quality (such as $w / c$ and concrete cover thickness). A much more efficient way is to seal cracks by resin injection before salt enters.

\section{Acknowledgements}

The research works belong to one part of the project which is financially supported by the Fundamental Research Funds for the Central Universities (2015XKMS011) and the National Science Foundation of China (51178455).

\section{References}

[1] Rob B Polder, Willy H.A Peelen. Characterisation of chloride transport and reinforcement corrosion in concrete under cyclic wetting and drying by electrical resistivity. Cement and Concrete Composites, Volume 24, Issue 5, October 2002, Pages 427-435

[2] Bassem Saassouh, Zoubir Lounis. Probabilistic modeling of chloride-induced corrosion in concrete structures using first- and second-order reliability methods. Cement and Concrete Composites, Volume 34, Issue 9, October 2012, Pages 1082-1093

[3] Vu Hiep Dang, Raoul François. Prediction of ductility factor of corroded reinforced concrete beams exposed to long term aging in chloride environment. Cement and Concrete Composites, Volume 53, October 2014, Pages 136-147

[4] Karla Hornbostel, Claus K. Larsen, Mette R. Geiker. Relationship between concrete resistivity and corrosion rate - A literature review. Cement and Concrete Composites, Volume 39, May 2013, Pages 60-72 
[5] Mahdi Valipour, Mohammad Shekarchi, Pouria Ghods. Comparative studies of experimental and numerical techniques in measurement of corrosion rate and time-to-corrosion-initiation of rebar in concrete in marine environments. Cement and Concrete Composites, Volume 48, April 2014, Pages 98-107

[6] Yun Yong Kim, Jin Man Kim, Jin-Wook Bang, Seung-Jun Kwon. Effect of cover depth, w/c ratio, and crack width on half cell potential in cracked concrete exposed to salt sprayed condition. Construction and Building Materials, Volume 54, 15 March 2014, Pages 636-645

[7] Dong Chen, Sankaran Mahadevan. Chloride-induced reinforcement corrosion and concrete cracking simulation. Cement and Concrete Composites, Volume 30, Issue 3, March 2008, Pages 227-238

[8] L. Hariche, Y. Ballim, M. Bouhicha, S. Kenai. Effects of reinforcement configuration and sustained load on the behaviour of reinforced concrete beams affected by reinforcing steel corrosion. Cement and Concrete Composites, Volume 34, Issue 10, November 2012, Pages 1202-1209

[9] Dale P. Bentz, Edward J. Garboczi, Yang Lu, Nicos Martys, Aaron R. Sakulich, W. Jason Weiss. Modeling of the influence of transverse cracking on chloride penetration into concrete. Cement and Concrete Composites, Volume 38, April 2013, Pages 65-74

[10] Ryu J S, Otsuki N. Application of electrochemical techniques for the control of cracks and steel corrosion in concrete. Journal of Applied Electrochemistry, 2002, 32: 635 - 639.

[11] Li, Chun-qing, Melchers R E, Zheng Jian-jun. Analytical model for corrosion-induced crack width in reinforced concrete structures. ACI Structural Journal, 2006, 103(4):479-487

[12] Otieno M B, Alexander M G, Beushausen H-D. Corrosion in cracked and uncracked concrete - influence of crack width, concrete quality and crack reopening [J]. Magazine of Concrete Research, 2010, 62(6): 393-404

[13] Schieß1 P, and Raupach M. Laboratory studies and calculations on the influence of crack width on chloride-induced corrosion of steel in concrete [J]. ACI Mat. J., 1997, 94(1): 56-61.

[14] Raupach M. Chloride-induced macrocell corrosion of steel in concrete -Theoretical Background and Practical Consequences [J]. Construction and Building Materials, 1996, 10(5):329-338

[15] ACI Committee 224 . ACI 224R-01 Control of Cracking in Concrete Structures. 2001

[16] GB/T 50476. Code for durability design of concrete structures. 2008

[17] Australian Standard. Concrete Structures. AS 3600-2009

[18] Comite' Euro-International du Be 'ton (CEB). "Durable concrete structures.” 1989

[19] Yong-sheng Ji, Wen Zhao, Min Zhou, Hui-rong Ma, Ping Zeng. Corrosion current distribution of macrocell and microcell of steel bar in concrete exposed to chloride environments. Construction and Building Materials, Volume 47, October 2013, Pages 104-110

[20] Goitseone Malumbela, Mark Alexander, Pilate Moyo. Interaction between corrosion crack width and steel loss in RC beams corroded under load. Cement and Concrete Research, Volume 40, Issue 9, September 2010, Pages 1419-1428

[21] T Vidal, A Castel, R François. Analyzing crack width to predict corrosion in reinforced concrete. Cement and Concrete Research, Volume 34, Issue 1, January 2004, Pages 165-174

[22] Gu, Ping ; Beaudoin, J.J.; Tumidajski, P.J.; Mailvaganam, N.P. Electrochemical incompatibility of patches in reinforced concrete. Concr. Int. 19 (1997) 68-72

[23] Francois, Raoul; Castel, Arnaud; Otsuki, Nobuaki; Miyazato, Shin-Ichi; Diola, Nathaniel B.; Suzuki, Hirotaka. Influences of bending crack and water-cement ratio on chloride-induced corrosion of main reinforcing bars and stirrups. ACI Materials Journal, v 98, n 3, p 276-278, May/June 2001

[24] Law, D.W.; Millard, S.G.; Bungey, J.H. Linear polarization resistance measurements using a potentiostatically controlled guard ring. NDT and E International, v 33, n 1, p 15-21, January 2000

[25] Broomfield, John P. Field measurement of the corrosion rate of steel in concrete using a microprocessor controlled unit with a monitored guard ring for signal confinement. ASTM Special Technical Publication, v 1276, p 91-106, Oct 1996 